ISSN 1981-416X

Licenciado sob uma Licença Creative Commons

\title{
Mídias digitais no contexto da formação de professores indígenas no curso de Pedagogia EaD-MT: problema a ser dialogado
}

Digital media in the context of indigenous teachers' training in the EAD-MT Pedagogy course: a problem to be discussed

\section{Maria Aparecida Rezende*}

Universidade Federal de Mato Grosso (UFMT), Cuiabá, MT, Brasil

\section{Resumo}

O propósito do texto é debater uma problemática situada no curso de Licenciatura em Pedagogia Educação a Distância, realizado pelo Instituto de Educação da Universidade Federal de Mato Grosso/Universidade Aberta do Brasil/Núcleo de Educação a Distância. O recorte privilegia a formação de professores, focalizando a participação de estudantes de duas etnias: A'uwẽ (Xavante) e Boe (Bororo) de MT. Algumas questões impulsionam o debate: as dificuldades destes professores pois em suas comunidades a internet não tem qualidade adequada para desenvolver as atividades do Ambiente Virtual de Aprendizagem; a ida aos polos se não têm bolsa para as despesas prementes na cidade; as dificuldades linguísticas, uma vez que as atividades do curso estão formuladas em Português e os professores possuem duas outras línguas, sendo que a língua portuguesa se constitui como uma segunda língua. São perguntas delineadoras que procuram caminhos, trilhas em busca de

*MAR: Doutora, e-mail: rezemelo@gmail.com 
um diálogo aberto, um debate que auxilie a enfrentar os desafios enfrentados pelo Curso que busca atender a diversidade sociocultural presente em Mato Grosso. As informações obtidas advêm de visitas nas aldeias, depoimentos das orientadoras acadêmicas que atendem aos polos e relatos dos próprios estudantes indígenas. Espera-se, com esse texto, construir um diálogo com profissionais da área do Ensino a Distância para que, juntos e por meio das mídias digitais, sejam encontradas alternativas para a permanência de estudantes indígenas nesta modalidade de ensino.

Palavras-chave: Mídias Digitais. Educação a Distância. Formação de Professores Indígenas.

\section{Abstract}

This text aims to debate a problem in the Pedagogy Distance Education course, offered by the Education Institute of the Federal University of Mato Grosso/Brazilian Open University/ Distance Education Center. The course focuses on training teachers from two ethnic groups: A'uwẽ (Xavante) and Boe (Bororo) from the state of Mato Grosso. Some questions foster this debate: the difficulties faced by the participants since in their communities the internet does not have the quality necessary to develop the activities of the Virtual Learning Environment; the lack of scholarship to cover expenses of participating in conferences and face-to-face classes in the city; the linguistic difficulties, since the activities of the course are done in Portuguese and the teachers speak two other languages, Portuguese being their second language. These questions outline ways, paths in the search for an open dialogue, a debate that will help to face the challenges the Course has come upon while seeking to meet the sociocultural diversity present in Mato Grosso. The information was obtained from visits to the villages, testimonies from academic advisors that monitor the academic stations and from reports given by the indigenous people. It is expected that this text will bring about a dialogue among professionals of the Distance Teaching area so that, together and through the digital media, alternatives can be found so the indigenous students in this teaching modality can remain in the course.

Keywords: Digital Media. Distance Education. Indigenous Teachers Training. 


\section{Introdução}

O Curso de Licenciatura em Pedagogia - Educação a Distância, Núcleo de Educação Aberta e a Distância, Universidade Federal de Mato Grosso, Universidade Aberta, Instituto de Educação - NEAD/UFMT/ $\mathrm{UAB} / \mathrm{IE}$, doravante Curso, apresenta um diferencial que é o lugar que ele ocupa na história da educação brasileira e em Mato Grosso. Há mais de vinte anos em vigência, tem sido orientador de todas as outras ofertas de formação de professores em pedagogia a distância. Assim, ele se destaca pelo seu pioneirismo e pelo compromisso social, pedagógico e político que o colocou no interior de vários municípios mato-grossenses.

Os pesquisadores Alonso e Preti, contribuem com o Curso, que foi gestado no NEAD em 1992 e foi um marco por ser o único Núcleo a desenvolver cursos a distância na Universidade. "Ao longo dos anos de 1993-1994, a equipe do Núcleo foi elaborando o projeto, discutindo com docentes, por área de conhecimento, a elaboração do material didático do curso" (ALONSO; PRETI, 2016, p. 317)1. Nesse meio tempo muitas reuniões foram realizadas com prefeitos, secretários de educação dos municípios que seriam beneficiados e também com a equipe de trabalho do curso. Os autores afirmam que "Em agosto de 1994, o curso foi criado pelo Conselho Diretor da UFMT (Resolução CD nº 088/ em 2/08/1994) e, em dezembro do mesmo ano, realizou-se o primeiro Vestibular Especial para selecionar os 350 professores que participariam do curso em sua fase experimental" (Ibidem).

\footnotetext{
${ }^{1}$ Informações acerca da história completa do NEAD encontram-se em um artigo dos autores nominado: "O Núcleo de Educação Aberta e a Distância da UFMT: uma mirada para um passado presente (1992-2005)". Revista Educação Pública. Cuiabá, v. 25, n. 59, p. 312-327, maio/ago. 2016. $\mathrm{O}$ texto leva os leitores aos diferentes caminhos trilhados por essa educação até chegar à história atual do Curso. Um percurso que revela comprometimento social, político e cultural com o trabalho docente do Estado de Mato Grosso e dos diversos municípios que tiveram a oportunidade de fazer parte desse processo educacional.
} 
Dessa forma, o Curso foi criado sustentando-se em uma base forte de dimensões profundas que conferiram a ele um destaque na história, acessando um patamar reconhecido nacional e internacionalmente no que se refere ao ciclo da educação escolarizada oferecido a distância. Foram momentos de muitas reuniões e decisões entre os docentes do Instituto de Educação da UFMT e, dentre eles, um grupo de professores comprometidos com a causa da democratização do acesso à educação. Esse debate foi alargado com diversos municípios e, assim, foram criados os polos ${ }^{2}$ para a abertura do curso logo após o vestibular. Para ingressar nesse curso, os candidatos e as candidatas deveriam estar em uma sala de aula, ou seja, o curso foi ofertado para professores em serviço.

De acordo com os professores Katia Alonso e Oreste Preti, em fevereiro de 1995 foi a aula inaugural do Curso de Licenciatura em Pedagogia a distância e o NEAD iniciava sua primeira experiência no País, conferindo-lhe a chancela de pioneiro nessa modalidade de educação. Esta é uma introdução do curso no interior do NEAD, mas já aponta a responsabilidade desse núcleo e dos docentes e parceiros que nele atuam até o momento (ALONSO, PRETI, 2016).

O presente estudo toma como recorte a turma 2017, pela sua especificidade e pela continuidade do compromisso com que o NEAD vem mantendo com o trabalho educacional e a formação de professores nas regiões distantes e de difícil acesso a um curso de graduação, seja pela distância ou pelo fator financeiro que impede muitos estudantes de virem estudar na capital.

\footnotetext{
2 Tomemos a nota de rodapé do artigo acima citado na página 317 para designar o que os autores chamam de polo. "Polo era tomado não no sentido do lugar onde se instala o Centro de Apoio aos estudantes e sim numa concepção regional, como aparecia nos documentos do governo de Mato Grosso, como municípios que são agrupados por características comuns (sociais, culturais, econômicas), ou por influência política de um município sobre os demais próximos, ou por interesses comuns, como no caso da oferta dos cursos de Licenciaturas para os professores em exercício".
} 


\section{Contextualizando a turma 2017 do curso de Licenciatura em Pedagogia —-modalidade a distância}

Inicialmente, faz-se necessário o esclarecimento de um conceito recentemente usado na história da educação a distância: mídias digitais. Tradicionalmente, o conceito era explicitado como Tecnologias de Informação e Comunicação - TIC. Entretanto, alguns educadores/pesquisadores da área vêm mudando para uma expressão com maior abrangência Mídias Digitais - MD.

As pesquisadoras dessa temática (SOUZA; AMANTE; CRUZ, 2016) apontam a necessidade de ampliação conceitual, pois trata-se de uma cultura digital que, em suas multiplicidades de linguagens, possibilitam a comunicação em rede e, dessa forma, as pessoas obtém um grande número de informações, potencializando as capacidades de elaborar conhecimentos, bem como um novo modo de ser e viver. As autoras assim descrevem os significados dessa nova modalidade comunicacional:

MD serão entendidas não apenas como hardware (a base material, suporte e meios de distribuição), ou software (os programas e aplicativos que nela rodam) ou artefatos (os produtos criados nos programas com os equipamentos), ou mesmo linguagens (as diferentes formas de expressão e seus gêneros em constante mutação e suas possiblidades de interação), mas também como cultura, que inclui as práticas sociais (modos de uso, consumo, apropriação e produção de informação) as quais se configuram em novos espaços e eventos a partir de habilidades e competências que são exigidas para a operação dessas várias instâncias (SOUZA; AMANTE; CRUZ, 2016, p. 110-111).

Essa ampliação que as MD permitem produz uma mudança de sentidos na atuação dos estudantes indígenas, protagonistas deste texto. Debater questões tecnológicas sem pensar em seu sentido ressignificado nos contextos sociais seria diminuir as vivências diferenciadas dos povos indígenas a um patamar inferior, sem levar em conta as questões culturais de cada povo. As MD vão tecendo uma rede que não permite perceber 
onde se começa ou finaliza a sua tessitura. As novas tecnologias vão se apresentando para as diferentes culturas e se misturando a elas, formando então novas facetas das mídias digitais. A linguista Eunice de Paula apresenta exemplos de como um canal digital como o e-mail tem sido apropriado pelo povo Apyãwa (Tapirapé): “outro exemplo de mensagem via e-mail também aponta para o uso de fórmulas de saudações, antes restritas às interações verbais, aparecendo na escrita" (PAULA, 2014, p. 161).

Mas seria preciso fazer um estudo com profundidade acerca dessa temática e registrar as novas informações, potencializando assim um novo conhecimento de mídias sendo apropriadas por povos etnicamente diferenciados.

O foco aqui é a turma que se iniciou em 2017. Consideramos que ela foi diferenciada porque, de acordo com o Edital N. ${ }^{\circ}$ 040/2016 PROEG/UFMT, favoreceu, por meio de cotas comprovadas no ato das inscrições, os indígenas, pretos e pardos, assim "3.3.4. Ação Afirmativa 4: Vagas destinadas a candidatos autodeclarados pretos, pardos ou indígenas que, independentemente da renda (art. 14, II, Portaria Normativa $\left.n^{\circ} 18 / 2012\right)$, tenham cursado integralmente o ensino médio em escolas públicas (Lei $\left.\mathrm{n}^{\circ} 12.711 / 2012\right)$ ). Nessa turma, entraram sete A'uwẽ (Xavante), três Boe (Bororo) e uma Kamayurá que cresceu entre os não indígenas em Canarana-MT.

O Edital teve divulgação em algumas aldeias, com visitas da coordenação do curso e do NEAD. Não foi possível ir em todas as aldeias interligadas aos polos de Primavera do Leste, Água Boa e Canarana, polos com concentração de povos indígenas mato-grossenses, mas os próprios indígenas fizeram a divulgação a seus parentes ${ }^{3}$.

Primavera do Leste fica distante de sua capital Cuiabá, aproximadamente $245 \mathrm{~km}$. Água Boa se distancia há quase $748 \mathrm{~km}$ da capital e Canarana situa-se um pouco mais longe, cerca de $838 \mathrm{~km}$. Há, ainda,

\footnotetext{
${ }^{3}$ Termo usado entre as etnias em suas batalhas por recuperação de territórios, elemento comum que os aproxima e os levam às mesmas lutas sociais e políticas de vida.
} 
comunidades indígenas em que moram estudantes do curso de Pedagogia cuja distância se aproxima de pouco mais de $900 \mathrm{~km}$.

As dificuldades iniciaram-se durante as inscrições. Precisavam de internet, mas em suas aldeias não havia rede e nem sinal, pelo menos na maioria delas. Muitos estudantes não puderam inscrever-se porque não conseguiram ir aos polos. Em algumas comunidades, o Estado oferecia internet nas escolas, mas segundo informações de alguns professores indígenas, durante as férias, a internet foi suspensa como medida de economia, o que refletiu de modo negativo no período das inscrições do vestibular do curso.

O curso iniciou-se com 240 estudantes nos quatro polos: Água Boa, Canarana, Juara (não tem estudante indígena) e Primavera do Leste. Deste total, dez estudantes indígenas, todos residentes nos três municípios mencionados. Vale ressaltar que, na turma 2012-2016, ingressaram seis estudantes Chiquitano, que estavam em maior contato com as duas línguas: português e espanhol, mas, ainda assim, enfrentaram sérias dificuldades para finalizar o curso. Dos seis, três conseguiram concluir o curso. Eles estudavam no polo de Jauru-MT.

\section{Interações entre diferentes concepções de educação}

No contexto de educação entre os povos indígenas, percebemos três concepções de educação: a que chamamos de "educação indígena", isto é, os processos educacionais presentes em cada sociedade indígena, a "educação escolar" tal como se apresenta na sociedade não indígena e a "educação escolar indígena" que propõe a instituição escolar inserida no modo de vida das diversas etnias. Estes três modelos estão ancorados num contexto sociocultural, destacando-se que o último vem sendo ressignificado pelos povos indígenas, que fazem uma apropriação e uma releitura da instituição escolar para enfrentar os desafios presentes nas relações com a nossa sociedade.

Para a leitura desse complexo contexto educacional, alicerçamo-nos epistemologicamente na fenomenologia merleau-pontyana, segundo a qual: 
É uma filosofia transcendental que coloca em suspenso, para compreendê-la, as afirmações da atitude natural, mas é também uma filosofia para a qual o mundo já está sempre "ali", antes da reflexão, como uma presença inalienável, e cujo esforço todo consiste em reencontrar esse contato ingênuo com o mundo, para dar-lhe enfim um estatuto filosófico (MERLEAU-PONTY, 2006, p. 1).

A educação indígena tem seu modo de pensar e agir. Além disso, esta possui suas próprias tecnologias, que deram suporte de vida aos povos indígenas interagirem com suas culturas e compreensão de mundo. O antropólogo Gersen da etnia Baniwa, ao referir-se à educação escolarizada, entende que é necessário "suspender" a educação escolar ocidental, organizada em moldes capitalistas e concebida de modo homogeneizador, no esforço de invisibilizar outra educação que a história colonialista ocultou durante muitos anos, não somente em termos de Brasil, mas no contexto da América Latina. Esses povos, a partir de uma colonialidade violenta, foram exterminados de modos diferentes ao longo da história da colonização. O direito de viver suas práticas educativas foram violados, exterminando vidas, línguas, culturas e estes povos foram coagidos a praticarem a cultura de seus colonizadores (LUCIANO, 2006).

É nesse contexto de deturpação de modos diferentes de viver que surge a educação escolar para os povos indígenas. São obrigados a falarem outra língua, abandonando as línguas originárias, praticarem outra religião e ocultarem as suas, submeterem-se a outras leis completamente divergentes das suas e, assim, foram agredidos em sua compreensão de ver o mundo e a relacionar-se com os outros viventes e não viventes, rompendo uma cosmovisão de natureza una entre todos os seres vivos (CASTRO, 1996).

Uma educação escolarizada impositiva, destruidora, desrespeitadora vai possibilitando o adentramento ao mundo das letras, da leitura de mundo feita de forma unilateral, com obrigatoriedade de seguir uma compreensão única, considerada como a superior. Uma escrita com sangue, com suor, com dor, com humilhações, com extermínio. Assim nasce a 
educação escolar para esses povos autóctones. Mas essa violência não foi recebida passivamente, houve muitas lutas de resistência e é isso que explica o extermínio de centenas de etnias somente no contexto brasileiro.

Para ilustrar essa tragédia, o antropólogo, professor doutor, indígena, portanto com autoridade para essa afirmação:

A história é testemunha de que várias tragédias ocasionadas pelos colonizadores aconteceram na vida dos povos originários dessas terras: escravidão, guerras, doenças, massacres, genocídios, etnocídios e outros males que por pouco não eliminaram por completo os seus habitantes. Não que esses povos não conhecessem guerra, doença e outros males. A diferença é que nos anos da colonização portuguesa eles faziam parte de um projeto ambicioso de dominação cultural, econômica, política e militar do mundo, ou seja, um projeto político dos europeus, que os povos indígenas não conheciam e não podiam adivinhar qual fosse (LUCIANO, 2006, p. 17).

Todos esses acontecimentos ocorreram quase que em paralelo a uma educação escolarizada para os povos indígenas, iniciando-se com os estudos bíblicos e suas traduções para que fossem "domesticados" e "amansados" para aceitar a escravidão do trabalho imposto pelos colonizadores. A chegada de Cabral ao Brasil representou um imenso genocídio, pois, segundo esse antropólogo, da estimativa de 5 milhões de pessoas à época a população foi reduzida a 350.000 pessoas, contabilizadas até bem pouco tempo. O linguista Aryon Rodrigues calculou o desaparecimento de $85 \%$ de línguas neste período, o que demonstra a violência do processo colonizatório implantado no Brasil (RODRIGUES, 1993).

Essas questões são importantes de serem tratadas antes de se historicizar o ingresso dos estudantes indígenas no Curso de Pedagogia $\mathrm{EaD}$, pois explicam as dificuldades que eles e todos os envolvidos no curso enfrentam, uma vez que são situações que ocorrem desde 1500, caracterizadas pelos modelos de educação impostos ou apropriados pelos povos indígenas. Atualmente, buscamos outros modos de atuar, por isso, o novo 
termo usado e pensado a respeito das tecnologias nos incentivam a um diálogo no sentido de compreensão das Mídias Digitais.

\section{O curso de Licenciatura em Pedagogia na modalidade a distância em vigor}

O Projeto Pedagógico do Curso prevê um currículo dialógico e político no sentido freireano: "a docência deve ser assumida como a base da formação do pedagogo e concebida para além da sala de aula" (PPC, 2012, p. 16). Isto implica no entendimento de diferentes formas de conhecimento que não sejam somente as acessadas na escola.

O PPC acentua em seu texto duas dimensões: a política e a pedagógica, inspirado nos autores André (2001) e Veiga (1998), afirma “[...] é pedagógico porque possibilita a efetivação da intencionalidade [do Curso de Pedagogia], que é a formação do cidadão participativo, responsável, compromissado, crítico e criativo" (PPC, 2012, p. 19), o que confere com sua prática educativa "[...] é político no sentido de compromisso com a formação do cidadão para um tipo de sociedade" (Ibidem). Esta compreensão também está ancorada no educador Paulo Freire em suas diversas obras publicadas. Uma educação que liberta a pessoa dos processos educacionais caracterizados pela opressão, quando os educandos e educandas conseguem fazer uma releitura de mundo e se percebem como sujeitos que produzem história e podem modificá-la.

Para esse autor a educação deve ser problematizadora e mediadas pelos homens-mundo. Em suas palavras: "como não há homens sem mundo, sem realidade, o movimento parte das relações homens-mundo" (FREIRE, 1987, p. 74). Esse movimento leva as pessoas ao encontro de sua tomada de consciência, apropriando de sua realidade histórica no sentido de sua transformação. Mas para isso é preciso realizar esse movimento com o povo e considerar também seus saberes e conhecimentos e não exaltar somente a ciência.

O filósofo Merleau-Ponty alerta sobre os cuidados que devemos ter com a análise de uma vivência, para não colocar a ciência acima dela, pois para ele o universo da ciência é construído sobre esse mundo vivido: 
"e se queremos pensar a própria ciência com rigor, apreciar exatamente e seu alcance, precisamos primeiramente despertar essa experiência do mundo da qual ela é a expressão segunda" (MERLEAU-PONTY, 2006, p. 3). Nesta compreensão, para o autor, a ciência é uma explicação do mundo. Para entender as realidades com as quais eu percebo, preciso entender o mundo. Qual é o mundo que os estudantes indígenas conhecem? Qual é o seu real? Podemos descrevê-lo? Podemos fazer uma reflexão acerca dessa experiência?

A reflexão, para a fenomenologia merleau-pontyana não pode me cegar ao ponto de não considerar os instrumentos culturais preparados por minha educação, minha própria história. Tudo isso para conhecer que o mundo e a experiência de cada pessoa nela vivido faz parte de uma vivência (MERLEAU-PONTY, 2006). Assim, os estudantes indígenas precisam entender esse novo processo a partir dos instrumentos educacionais que eles conhecem, aqueles que são parte da sua história e de sua educação. Para ilustrar a diferença entre a educação escolar e a educação indígena, na sequência, citaremos alguns elementos primordiais.

A educação indígena segue orientações dos ciclos da vida, além de seguir alguns princípios e ações educacionais como o exemplo recebido; a repetição das atividades desenvolvidas até que a pessoa aprenda. Não há um tempo igual para aprender (como é na educação escolar), não há um único espaço, pois os ensinos e as aprendizagens ocorrem o tempo todo. As festas e rituais são lições para ser um bom Apyãwa, um bom Iny, um bom xavante, um bom chiquitano e assim por diante. O silêncio, o exercício de escutar, fazem parte da educação. A paciência e a persistência são princípios fundantes do ato de educar.

A promulgação da Constituição de 1988 possibilitou aos povos indígenas a esperança de buscar sua história, ter o reconhecimento da cidadania indígena brasileira, a valorização de suas culturas, sem envergonharem-se do seu atuar, com consciência étnica, orgulho identitário de pertencer a um povo específico, como a um Trumai, um Aweti, um 
Kamayurá. Serem tratados como sujeitos de direito na sociedade vigente, tudo isso são marcos históricos de muitas conquistas políticas, culturais, econômicas e sociais. A conquista do território para viver é outro elemento fundamental, pois é o que fortalece o ato educativo de um povo. Sem ele, a educação torna-se difícil, uma vez que todos os elementos próprios de uma cosmogonia estão presentes no seio de um território.

A partir da compreensão de que os povos indígenas estavam com seus direitos garantidos pela Constituição Federal (BRASIL, 1988), pela Lei de Diretrizes e Bases da Educação Nacional — LDBEN, n. 9.394/1996 (BRASIL, 1996) e outros documentos legais, as pessoas foram reivindicando seus direitos a uma efetiva educação escolar que respeitasse a sua educação étnica. Os movimentos sociais indígenas foram se organizando e, atualmente, usam os meios tecnológicos para compor essa frente de luta. Eles viram na $\mathrm{EaD}$ a possibilidade de ter mais professores indígenas formados por uma universidade.

O curso em questão tem como base, em sua proposta curricular, alguns princípios que auxiliam na concretização de uma prática flexível ao longo da formação de professores pedagogos. Assim o PPC se diferencia:

Ao se propor abandonar a "disciplinaridade", trabalhando por áreas do conhecimento e, assim, oferecer uma formação interdisciplinar; no momento das opções quanto aos recortes teórico-metodológicos das áreas, tendo como referência comum os conceitos de historicidade, identidade, interação e construção; - na unidade teoria-prática: ao propor uma sólida formação teórica que possibilite a compreensão do fazer pedagógico, enraizada nas práticas pedagógicas, nos saberes profissionais, evitando-se a clássica separação entre os conteúdos e as metodologias (PPC, 2012, p. 24).

Seguindo essa orientação curricular, o curso é organizado em três núcleos, quais sejam: Núcleo Fundamentos da Educação no qual as áreas de conhecimento são apresentadas aos estudantes como elementos constitutivos para compreenderem a formação deles. O Núcleo Ciências Básicas e Metodologias, formado pelas ciências que embasam um processo 
educativo. E, por fim, o Núcleo Gestão e Trabalho Pedagógico na Educação que é constituído pela discussão dos aspectos institucionais e organizacionais da educação.

Esses núcleos possibilitam uma formação para além de contextos e espaços considerados escolares. São dinâmicos e os estudantes têm a possibilidade de participar da proposta do curso. No início do curso, o projeto pedagógico é distribuído aos estudantes, pois é parte integrante do material didático a ser estudado, visando a compreensão de como é o percurso da caminhada que os estudantes precisam realizar por meio da chamada "educação a distância". Mais: eles podem conferir como são realizados seus estudos como a autonomia de estudar sozinhos, técnicas de estudos e a metodologia do trabalho científico. Encerra-se esse primeiro momento com a realização de um Seminário Integrador (PPC, 2012). Assim, o estudante pode sentir-se pertencente à universidade pública da qual faz parte, esta que abarca o estudo das dimensões dos conhecimentos que o auxiliarão na compreensão de conceitos e definições que os fazem docentes, colaborando para a construção de sua história e o entendimento dos processos educativos dessa formação.

Os estudantes não estão sozinhos e nem "distantes" nessa empreitada, do início ao final do curso. Eles são acompanhados pelas orientadoras acadêmicas ${ }^{4}$ que os recebem em seus polos. Eles estudam o material que está disponibilizado no Ambiente Virtual de Aprendizagem (AVA); o fascículo de cada área de conhecimento impresso - material principal dos estudos - outros materiais complementares e, quando têm dificuldades, procuram suas orientadoras para sanar as dúvidas.

Os estudantes ainda têm os docentes formadores, responsáveis por cada área de conhecimento, para sanar dúvidas via e-mail ou no próprio AVA. Também há os coordenadores pedagógicos, docentes que fazem o elo entre as orientadoras acadêmicas e a coordenação do curso. Todas as

\footnotetext{
${ }^{4}$ Nessa turma só temos orientadoras acadêmicas mulheres.
} 
semanas há reunião pedagógica intercalada, ora com o colegiado do curso, ora com o Núcleo Docente Estruturante (NDE).

O curso tem uma equipe pedagógica comprometida e tem como parceiros permanentes a Secretaria de Tecnologia Educacional e as prefeituras, todas parceiras do NEAD/UAB/UFMT/IE. Os problemas não residem nessa dimensão de parcerias, mas são de outra natureza e também podem estar ligados à questão das parcerias, mas se mostram diferentes, como veremos a seguir.

\section{Em busca de dialogar acerca das dificuldades no interior do curso}

De volta aos questionamentos iniciais acerca das problemáticas apontadas em relação aos estudantes indígenas, o que tem preocupado a equipe pedagógica é como manter esses estudantes em um curso que não é específico para a formação de professores indígenas. Mas de acordo com depoimentos de estudantes indígenas, por ocasião da visita em suas aldeias, "[...] minha comunidade está feliz porque estou estudando em uma Universidade Federal”, ou o "[...] curso está muito difícil, mas a professora explica muito minhas dúvidas", narrativas de um estudante referindo-se à orientadora acadêmica que o atende em seu polo. "O sonho da minha comunidade é me ver formado nesse curso, porque ele é bom e está mostrando o que é ser um professor. Igual a nossa educação que mostra o que é ser um bom Xavante".

Em reunião com algumas comunidades ${ }^{5}$ onde convivem nossos estudantes, destacamos três objetivos específicos para estes encontros: 1. Esclarecer às comunidades indígenas sobre a responsabilidade da Universidade e do curso; 2. Enfatizar a responsabilidade do estudante

\footnotetext{
${ }^{5}$ No mês de abril de 2018 a coordenação do curso foi em todas as comunidades para conversar com os caciques, lideranças indígenas e com os estudantes, para entender quais eram as dificuldades que enfrentavam e o porquê das ausências de alguns estudantes nos polos, para tirar dúvidas ou mesmo participar de alguns momentos do curso, com obrigatoriedade da presença dos participantes. Além disso, havia também o atraso no desenvolvimento das atividades do AVA.
} 
indígena no processo de seu estudo; e 3. Expressar sobre a responsabilidade das comunidades envolvidas.

Nessa viagem comprovamos o quanto esse curso é importante para essas comunidades e para os estudantes. O vestibular diferenciado configura-se como uma conquista institucional e dos povos indígenas e quilombolas e das cotas para a educação escolar pública a registrar.

$\mathrm{Na}$ aula inaugural, um Xavante disse "[...] tenho que aprender a ciência do branco para ajudar minha comunidade" (Entrevistado 1, 20/04/2017). "A faculdade é uma conquista para a minha aldeia" (Entrevistado 2, 20/04/2017). O pensamento destes professores indígenas mostra que a conquista não é para si, mas para a coletividade. A entrada na universidade é, para eles, um meio de auxiliar o caminhar do seu povo, da sua comunidade.

Em reunião nas aldeias, os estudantes afirmaram que o curso é um sonho que está sendo realizado. Que os estudos estão contribuindo, aos poucos, para construir sua autonomia e buscar a autonomia do trabalho de suas comunidades, com gestores dos órgãos competentes. Os caciques enfatizam a importância do desenvolvimento da sua cultura, aliado aos trabalhos da escola. Pedem para a universidade ensinar os estudantes a elaborarem documentos (esses documentos são os oficiais, como ofícios, memorandos e outros). Os estudantes disseram que estão felizes no curso e que os atendimentos das orientadoras acadêmicas são excelentes, pois elas relevam com paciência a dificuldade com a segunda língua que é a portuguesa. Parabenizaram o curso, pois não esperavam tanta consideração comparando com os cursos superiores que alguns indígenas fizeram e nos quais sofreram preconceito e discriminação. Ao falar das responsabilidades, abordaram as dificuldades e todas atestadas pelos caciques. Mas foram unânimes os pedidos das comunidades para a universidade auxiliar seus estudantes a não desistirem do curso e o concluírem. Disseram que as comunidades ganharão profissionais competentes sem precisar contratar professores waradzu (não indígena). Isto porque, de modo geral, os nãos indígenas não conseguem viver nas aldeias; não entendem a cultura 
e fazem da educação escolar um instrumento pedagógico carregado de autoridade, desrespeitando a educação indígena.

Nessas reuniões, foram elencadas algumas dificuldades pelos estudantes frente à sua comunidade, e pelas lideranças que também fizeram seus pedidos. Os estudantes expuseram três situações:

1) A comunidade não tem carro para transportá-los até a cidade para os atendimentos presencias nos polos. Quando alguém tem um carro para levá-los à cidade, precisa de combustível para o deslocamento e eles não têm dinheiro para isso, semanalmente;

2) Ausência de internet adequada para realizar as atividades. Quando esta existe, é muito debilitada para desenvolver os estudos, pois há necessidade de assistir filmes, documentários e outras atividades que precisam ser realizadas ao longo de cada área de conhecimento;

3) Dificuldades linguísticas: os Xavante expressaram que não conseguem compreender bem os textos porque a língua portuguesa é muito difícil e diferente da língua A'uwẽ. Muitas vezes, eles estão compreendendo o conteúdo por meio da leitura, mas não conseguem expressar esse entendimento por falta de vocabulário. Esse problema é relevante, uma vez que aos povos indígenas é garantido o uso de suas línguas originárias nos processos educacionais (Art. 210 e 231 da Constituição Federal de 1988). Como aponta a linguista Terezinha, para os indígenas, o bilinguismo é compulsório, isto é, diante da situação de contato, eles necessitam se apropriar da língua da sociedade dominante (MAHER, 2007). Esta mesma autora enfatiza a necessidade de um bilinguismo aditivo, no qual as duas línguas se situem num mesmo patamar, uma não se sobrepondo à outra.

Em relação às responsabilidades das comunidades, todas as lideranças e caciques afirmaram acompanhamento dos seus estudantes. Além disso, confirmaram as mesmas dificuldades enfrentadas pelos acadêmicos e atestaram que todos eles são responsáveis e lideram suas comunidades. 
Também, que os alunos estão interessados pelo curso e tudo o que eles realizam durante os estudos, seja no ambiente virtual de aprendizagem (AVA) ou nos momentos presenciais quando têm atividades nos polos, são apresentados às comunidades por meio do Warã ${ }^{6}$.

A visita na aldeia dos estudantes Boe, conhecida como povo Bororo, foi para escutar suas dificuldades e também para coletar as assinaturas de dois deles, que desistiram do curso. Os alunos disseram que foi uma decisão sofrida, pois estavam gostando muito do curso, mas não têm dinheiro para as passagens semanais para irem ao polo de Primavera do Leste, que fica muito distante de sua aldeia. Foi um momento doloroso para todos. Dos três estudantes, ficou apenas uma mulher.

\section{Considerações finais}

Apesar do pouco tempo em área, foi importante essa visita para ver de perto a dimensão dos problemas que assolam nossos estudantes. O compromisso com as comunidades foi firmado e foi constatado que os alunos realmente não vão aos polos devido à dificuldade financeira para o transporte ou para a sustentação na cidade (hospedagem e alimentação). Em relação a essa problemática, os problemas serão levantados e debatidos sobre como encaminhá-los para uma resolução.

${ }^{6}$ Entendo o Warã como uma assembleia masculina que representa a opinião de toda a comunidade. São realizadas duas reuniões ao dia: a primeira antes do amanhecer, por volta das $5 \mathrm{~h}$, momento de planejamento das atividades a se realizarem durante o dia. A segunda, por volta das $18 \mathrm{~h}$, momento de avaliar todas os trabalhos desenvolvidos durante o dia, seja na aldeia ou na cidade. Tudo é relatado em detalhes para as tomadas de decisão. As reuniões não têm hora para terminar, depende da quantidade de assunto e de sua profundidade. O cacique não pode tomar decisões por si mesmo, ele é apenas um membro do Warã e voz da comunidade para levar as decisões às instâncias constituídas pelos não indígenas. As autoridades máximas são os conselheiros anciões. Eles são escutados em suas decisões finais. Warã, portanto, é uma instância política que decide os assuntos em pauta e delibera decisões, assim é consultivo e deliberativo. 
Em relação ao problema da internet (muito fragilizada), uma alternativa vislumbrada é a de discutir com os secretários de educação dos municípios ou com o secretário de educação do Estado acerca dessa parceria, já que algumas escolas são também estaduais. Faltam computadores nas escolas indígenas, por isso o impedimento de alguns estudantes realizarem suas atividades no AVA.

O problema relacionado à questão linguística nos parece mais complexo, uma vez que os materiais de estudo estão impressos em língua portuguesa, língua que os professores indígenas precisam dominar, uma vez que a eles é solicitado o serviço de elaboração de documentos reivindicatórios dirigidos às autoridades não indígenas. Para chegar a uma solução satisfatória, deveria haver intérpretes bilíngues para auxiliar no desenvolvimento das atividades propostas.

Diante de todos os problemas relatados, percebemos o quanto as comunidades consideram muito o ensino superior e a importância da EaD por meio da UAB. Mas a política pedagógica dos cursos, com atendimento a pessoas pobres (comprovadamente) do campo e indígenas, necessita ser repensada e readaptada. Como vimos, as condições financeiras e pedagógicas exigidas pelo modelo atual de EaD não são adequadas para pessoas que vivem no campo ou em comunidades indígenas.

Diante das dificuldades mencionadas, é necessária a discussão que aborde as Mídias Digitais por pesquisadores e técnicos que trabalham na área, a partir dos relatos apresentados ao longo dos cursos em desenvolvimento, para que possam pensar em alternativas para buscar soluções ao enfrentamento dos desafios que aparecem no decorrer das trajetórias dos cursos.

Em relação ao curso de Pedagogia, foi constatado que o currículo atende às necessidades pedagógicas dos estudantes. Não obstante, mesmo com o esforço de metodologias diferenciadas ofertadas, ainda assim o curso não consegue enfrentar todas as demandas. Mas seguimos com o debate em questão, numa atitude dialógica e discussão política para minimizar os problemas que assolam o curso e evitar as desistências dos 
estudantes indígenas, além de outros alunos que também demonstram estar com problemas semelhantes.

\section{Referências}

ALONSO, K. M.; PRETI, O. O Núcleo de Educação Aberta e a Distância da UFMT: uma mirada para um passado presente (1992-2005). Revista Educação Pública, Cuiabá, v. 25, n. 59, p. 312-327, maio/ago. 2016.

BRASIL. Constituição da República Federativa do Brasil de 1988. 35. ed. Brasília: Biblioteca Digital Câmara dos Deputados, 2012. Disponível em: <http://bd.camara.gov.br/bd/bitstream/handle/bdcamara/.../constituicao_ federal_35ed.pdf?>.

BRASIL. Senado Federal. Lei de Diretrizes e Bases da Educação Nacional. Brasília, Senado Federal, 1996.

BRASIL. Ministério da Educação e do Desporto. Secretaria de Educação Fundamental. Referencial Curricular Nacional para as Escolas Indígenas. Brasília, MEC/SEF, 1988.

CASTRO, E. V. Os pronomes cosmológicos e o perspectivismo ameríndio. ManaEstudos de Antropologia Social, Rio de Janeiro, v. 2, n. 2, p. 115-144, 1996.

FREIRE, P. Pedagogia do oprimido. 17.ed. Rio de Janeiro: Paz e Terra, 1987.

LUCIANO, G. S. O índio brasileiro: o que você precisa saber sobre os povos indígenas no Brasil de hoje. Brasília, DF, Ministério da Educação, Secretaria de Educação Continuada, Alfabetização e Diversidade: LACED/Museu Nacional, 2006.

MAHER, T. M. Do casulo ao movimento: a suspensão das certezas na educação bilíngüe e intercultural. In: CAVALCANTI, M. C.; BORTONI-RICARDO, S. M. Transculturalidade, linguagem e educação. Campinas: Mercado de Letras, 2007.

MERLEAU-PONTY, M. Fenomenologia da percepção. 3. ed. São Paulo: Martins Fontes, 2006. 
PAUlA, E. D. A língua dos Apyãwa - Tapirapé - na perspectiva da Etnossintaxe. Campinas: Editora Curt Nimuendaju, 2014.

PROJETO DO CURSO: LICENCIATURA EM PEDAGOGIA MODALIDADE A DISTÂNCIA. Núcleo de Educação Aberta e a Distância/Instituto de Educação/ UFMT. EdUFMT: Cuiabá, 2012.

RODRIGUES, A. D. Línguas Indígenas: 500 anos de descobertas e perdas. Revista D.E.L.T.A., v. 9, n. 1, 1993.

SOUZA, T. F.; AMANTE, L.; CRUZ, D. M. Formação de professores na perspectiva dos letramentos/literacias digitais: potencialidades para a educação a distância. In: MACIEL, C.; ALONSO, K. M.; PEIXOTO, J. (Org.). Educação a distância: experiências, vivências e realidades. Cuiabá: EdUFMT, 2016. p. 109-150.

Recebido: 31/07/2018

Received: 07/31/2018

Aprovado: 08/02/2019 Approved: 02/08/2019 